\title{
Assessment of Role of Human Papilloma Virus in Patients with Oral Squamous Cell Carcinoma
}

\author{
Krishan Kumar Tyagi, ${ }^{1}$ Megha Pradhan, ${ }^{2}$ Rajbir Kaur Grewal, ${ }^{3}$ Prabesh Sherchan, ${ }^{4}$ K.S.A Pasha ${ }^{5}$ \\ ${ }^{1}$ Department of Oral Pathology, ${ }^{2}$ Department of Pedodontics, Kathmandu Medical College, Sinamangal, Kathmandu, \\ Nepal, ${ }^{3}$ Department of Oral Pathology, Desh Bhagat Dental College \& Hospital, ${ }^{4}$ Department of Orthodontics, \\ Kathmandu Medical College, Sinamangal, Kathmandu, Nepal, ${ }^{5}$ Department of Prosthodontics , College of Medical \\ Sciences, Chitwan, Nepal.
}

\begin{abstract}
Background: Head and neck malignancies include malignancies instigating in the oral cavity, the oropharynx, the hypopharynx and the larynx. We planned the present study to assess the role of human papilloma virus (HPV) in patients with oral squamous cell carcinoma (OSCC). Methods: The present study included assessment of role of human papilloma virus in patients with oral squamous cell carcinoma. A total of 50 histopathologic proven cases of well differentiated OSCC were included in the present study. A total of 50 healthy oral mucosal tissues (controls) were also included in the present study. The controls were obtained while surgical removing the impacted teeth. DNA was obtained from the tissue sections and underwent polymerization chain reaction for identification of HPV 16/18. All the results were summarized in Microsoft excel sheet and were analyzed by SPSS software. Results: HPV was absent in all the cases of control group, whereas among the OSCC group, the HPV was detected in 46 percent of the cases. In the remaining 54 percent of the cases of the OSCC group, HPV was absent. Significant results were obtained while comparing the presence of HPV in between the OSCC group and the control group. Conclusions: HPV was present in significant number of OSCC cases. Therefore; HPV might play a contributing role in the etio-pathogenesis of OSCC.
\end{abstract}

Keywords: cell carcinoma; human papilloma virus; oral squamous.

\section{INTRODUCTION}

Head and neck malignancies include malignancies instigating in the oral cavity, the oropharynx, the hypopharynx and the larynx. In the general population,oral cancer is the sixth most common cancer for both sexes and the third most common cancer in developing nations. Carcinomas account for $96 \%$ of all oral cancers, $91 \%$ of which are oral squamous cell carcinomas (OSCCs). ${ }^{1-3}$ The 5 -year survival rate for oral cancers is one of the lowest, far below the rate for many other general body cancers, including skin melanomas and cancer of the testis, breast, colon, rectum and kidneys. ${ }^{4} \mathrm{HPV}$ is a $55 \mathrm{KD}$, nonenveloped, double-stranded, circular DNA virus that has been implicated in a variety of anogenital and aerodigestive diseases, ranging from common warts to laryngeal papilloma to cervical cancer. ${ }^{5,6}$ More than 120 different subtypes of HPV have been identified which are divided into 3 major groups as super Group A (Alpha papillomavirus), super Group B (Beta papilloma virus), and the remaining group of HPVs are members of super Group E (Mu and Nu-papilloma viruses). ${ }^{7-9}$ Hence; we planned the present study to assess the role of human papilloma virus (HPV) in patients with oral squamous cell carcinoma (OSCC).

\section{METHODS}

The present study was carried out in the department of oral pathology of M.B. Kedia Dental College Pvt. Ltd., Birgunj between September 2017 to January 2019 and it included assessment of role of human papilloma virus in patients with oral squamous cell carcinoma. Ethical approval was obtained from the institutional ethical committee in written before the starting of the study. A total of 50 histopathologic proven cases of well differentiated OSCC were included in the present study. A total of 50 healthy oral mucosal tissues (controls) were also included in the present study. The controls were obtained while surgical removing the impacted teeth. Complete demographic and clinical detail of all the cases was obtained. Sample selection criteria: Only those patients were selected in our study that had not undergone any

Correspondence: Dr. Krishan Kumar Tyagi, Department of Oral Pathology, ${ }^{2}$ Department of Pedodontics, Kathmandu Medical College, Sinamangal, Kathmandu, Nepal Email: krish.krish621@gmail.com. Phone: +977-9816210299. DOI:10.3126/jcmsn.v15i2.22707. Article received: 2019-02-19. Article accepted: 2019-05-19. 
Tyagi et al. Assessment of Role of Human Papilloma Virus in Patients with Oral Squamous Cell..

radiotherapy, chemotherapy and surgical treatment. Patient had a history of recurrent OSCC or any earlier treatment were excluded from the study. Tissue sample collection: After following the inclusion \& exclusion criteria, incisional biopsy was done for clinical suspected cases of oscc. Tissue was stored in 10\% neutral buffered formalin $\&$ later formalin fixed paraffin -embedded blocks were prepared. Biological tissue will be cut with 5 um thickness, stained with Haemotoxylin \&Eosin Stain. After confirmation of OSCC, DNA extraction was done using modified proteinase $\mathrm{K}$ method ${ }^{10}$ and was stored at $-80^{\circ} \mathrm{C}$ till further analyzed for identification of HPV 16/18. All the results were summarized in Microsoft excel sheet and were analyzed by SPSS software. Chi- square test was used for assessment of level of significance. Pvalue of less than 0.05 was taken as significant.

\section{RESULTS}

A total of 50 OSCC cases and 50 oral mucosal controls were included in the present study. Mean age of the OSCC patients was 48.6 years, with majority of the cases being the range of 40 to 60 years. 52 percent of the OSCC cases belonged to the age group of 40 to 60 years, whereas 40 percent of the cases belonged to the age group of more than 60 years. 8 percent of the cases were of less than 40 years of age. 58 percent of the cases of the OSCC group were males, while the remaining 42 percent of the cases of the OSCC group were females (Table 1).

In the present study, HPV was absent in all the cases of control group, whereas among the OSCC

\begin{tabular}{|llc|}
\hline Table 1. Demographic data. & \\
\hline Parameter & & OSCC cases \\
Age group & Less than 40 & 4 \\
(years) & 40 to 60 & 26 \\
& More than 60 & 20 \\
Gender & Males & 29 \\
& Females & 21 \\
\hline
\end{tabular}

group, the HPV was detected in 46 percent of the cases. In the remaining 54 percent of the cases of the OSCC group, HPV was absent. Significant results were obtained while comparing the presence of HPV in between the OSCC group and the control group (Table 2).

\begin{tabular}{|lccc|}
\hline Table & 2. Detection of HPV in both the study groups. \\
\hline HPV & OSCC group $(\mathrm{n}=50)$ & Control group $(\mathrm{n}=50)$ & $\mathrm{p}$ - value \\
Present & 23 & 0 & \\
Absent & 27 & 50 & $0.02($ Sig) \\
\hline
\end{tabular}

\section{DISCUSSION}

In the present study, a total of 50 OSCC cases and 50 oral mucosal controls were included in the present study. Mean age of the OSCC patients was 48.6 years, with majority of the cases being the range of 40 to 6 years. In a previous study conducted by Cao $\mathrm{J}$ et al, authors assessed the incidence of occurrence HPV 16/18 infection in OSCC patients. They also evaluated the association of HPV incidence and alteration in p53 in OSCC patients.In their study, a total of 40 OSCC cases and 20 normal oral mucosa tissue (controls) were assessed. Identification of HPV 16 and 18 and p53 in their study was done by PCR and immunohistochemistry. In 72.5 percent of the tissue specimens of their study, they detected the presence of HPV. They observed significantly higher HPV expression in the study group in comparison to the control group. In 45 percent of the OSCC cases of their study, they noticed alternated p53 activity. However; they didn't observed any significant association between HPV infection and p53 alteration. From the results, they concluded that HPV16/18 infection and/or p53 alterations are strongly correlated with OSCC. ${ }^{11}$

52 percent of the OSCC cases belonged to the age group of 40 to 60 years, whereas 40 percent of the cases belonged to the age group of more than 60 years. 8 percent of the cases were of less than 40 years of age. 58 percent of the cases of the OSCC group were males, while the remaining 42 percent of the cases of the OSCC group were females. In the present study, HPV was absent in all the cases of control group, whereas among the OSCC group, the HPV was detected in 46 percent of the cases. In another study conducted by Penhallow $\mathrm{J} t$ al, authors assessed the correlation between HPV infections and p53 gene aberrations in 28 OSCC cases and 12 potentially malignant oral mucosal lesions (PMOMLs). Analysis was done by immunohistochemistry and PCR. Overexpression of p53 was identified in 50 percent of the OSCC cases and 22 percent of the PMOMLs. Their results demonstrated that both p53 alterations and HPV infection might be significant etiological factors in the development of OSCC. ${ }^{12}$ In contradiction to the previous studies, Young and Min et $\mathrm{al}^{13}$. and Tsuchiya et al. ${ }^{14}$ were unable to find such association between HPV 16 and OSCC. Recently, systematic review by Syrjänen et al. ${ }^{15}$ in 2011 in their review from 1966 to 2010 showed strong correlation between the presence of HPV DNA, specifically with HPV16 and OSCC In the present study, HPV was absent in the remaining 54 percent of the cases of the OSCC group. 
Tyagi et al. Assessment of Role of Human Papilloma Virus in Patients with Oral Squamous Cell..

Significant results were obtained while comparing the presence of HPV in between the OSCC group and the control group. In another previous study conducted by Oliveira MC et al, authors assessed the incidence and variety of HPV in OSCC cases. They also examined the pattern of expression of p53 and bcl-2 in OSCC cases. By PCR, they observed that 29.5 percent of the cases were positive for HPV. However; by performing dot blot hybridization, it was observed that 80.8 percent of the cases were positive for HPV 18 and
3.8 percent of the cases were positive for HPV 16. From the results, they concluded that HPV plays a definitive role in the development of OSCC. ${ }^{16}$

\section{CONCLUSIONS}

Under the light of above obtained results, the authors observed the presence of HPV in significant number of OSCC cases. Therefore; HPV might play a contributing role in the etiopathogenesis of OSCC. However; further research is directed for better exploration of results.

\section{REFERENCES}

1. Muller PA, Vousden KH. Mutant p53 in cancer: New functions and therapeutic opportunities. Cancer Cell. 2014;25:304-317.

2. Martinez SL, Gomez GE, Trapero JC, Rodriguez PC, Martinez AB, Moreno- Lopez LA et al. Genotypic Determination by PCR-RFLP of Human Papillomavirus in Normal Oral Mucosa, Oral Leukoplakia and Oral Squamous Cell Carcinoma Samples in Madrid (Spain). Anticancer Res 2008;28:3733-42.

3. Rybanska I, Ishaq O, Chou J, et al. PARP1 and DNA-PKes synergize to suppress p53 mutation and telomere fusions during $\mathrm{T}$-lineage lymphomagenesis. Oncogene. 2013;32:17611771.

4. Agrawal U, Rai H, Jain AK. Morphological and ultrastructural characteristics of extracellular matrix changes in oral squamous cell carcinoma. Indian J Dent Res. 2011;22:16-21.

5. Sikka S, Sikka P. Association of human papilloma virus 16 infection and p53 polymorphism among tobacco using oral leukoplakia patients: A clinicopathologic and genotypic study. Int J Prev Med 2014;5:430-8.

6. Li Y, Yang K, Zhang J, Zhang F, Chen R, Deng D. Clinical study of chron-chemotherapy together with arterial chemotherapy for oral and maxillofacial squamous cell carcinoma. Kouqiang Yi Xue Yan Jiu. 2007;23:668-670.

7. Hou J, Gu Y, Hou W, Wu S, Lou Y, Yang W, et al. P53 codon 72 polymorphism, human papillomavirus infection, and their interaction to oral carcinoma susceptibility. BMC Genet 2015;16:1-9.

8. Miller CS, Johnstone BM. Human papillomavirus as a risk factor for oral squamous cell carcinoma: A meta-analysis, 1982-1997. Oral Surg Oral Med Oral Pathol Oral RadiolEndod 2001;91:622-35.

9. Mravak-Stipetic M, Sabol I, Kranjcic J, Kneževic M, Grce M. Human papillomavirus in the lesions of the oral mucosa according to topography. PLoS One 2013;8:e69736.

10.Pitera R, Pitera JE, Mufti GJ, Salisbury JR . Modification of standard proteinase $\mathrm{K} / \mathrm{phenol}$ method for extraction of DNA from small tumour biopsies . Pathol Res Pract. 1993 Sep;189 (8):882-7

11.Cao J1, Zhang ZY, Patima, Zhang YX, Chen WT. Human papillomavirus infection and p53 alteration in oral squamous cell carcinoma. Chin J Dent Res. 2000 Nov;3(3):44-9.

12.Penhallow J1, Steingrimsdottir H, Elamin F, Warnakulasuriya S, Farzaneh F, Johnson N, Tavassoli M. p53 alterations and HPV infections are common in oral SCC: p53 gene mutations correlate with the absence of HPV 16-E6 DNA. Int J Oncol. 1998 Jan;12(1):59-68.

13. S. K. Young and K. W. Min, "In situ DNA hybridization analysis of oral papillomas, leukoplakias, and carcinomas for human papillomavirus," Oral Surgery Oral Medicine and Oral Pathology, vol. 71, no. 6, pp. 726-9, 1991.

14.H. Tsuchiya, Y. Tomita, H. Shirasawa, H. Tanzawa, K. Sato, and B. Simizu, "Detection of human papillomavirus in head and neck tumors with DNA hybridization and immunohistochemical analysis," Oral Surgery Oral Medicine and Oral Pathology, vol. 71, no. 6, pp. 721-5, 1991

15. S. Syrjänen, G. Lodi, I. von Bültzingslöwen et al., "Human papillomaviruses in oral carcinoma and oral potentially malignant disorders: a systematic review," Oral Diseases, vol. 17, no. 1, pp. 58-72, 2011

16. Oliveira MC1, Soares RC, Pinto LP, Souza LB, Medeiros SR, Costa Ade L. High-risk human papillomavirus (HPV) is not associated with p53 and bcl-2 expression in oral squamous cell carcinomas. AurisNasus Larynx. 2009 Aug;36 (4):450-6.

Citation: Tyagi KK, Pradhan M, Grewal RK, Sherchan P, Pasha KSA. Assessment of Role of Human Papilloma Virus in Patients with Oral Squamous Cell Carcinoma. JCMS Nepal. 2019; 15(2):125-7. 